\title{
Sociology in a Changing Climate
}

\author{
by Elizabeth Shove \\ Lancaster University
}

Sociological Research Online, 15 (3) 12

$<$ http://unw. socresonline.org.uk/15/3/12.htm/>

$10.5153 /$ sro. 2218

Received: 17 Aug 2010 Accepted: 19 Aug 2010 Published: 31 Aug 2010

\begin{abstract}
This note responds to John Urry's contribution and draws on my own presentation at the BSA Presidential Event on 'How to put 'Society' into Climate Change', held on 8th February 2010 at the British Library.
\end{abstract}

\section{Introduction}

1.1 In his paper John Urry issues ten commandments designed to engender a sociology of climate change and ensure that the discipline establishes a place for itself in "urgent academic and policy debates". I begin by wondering whether such a call to arms is really what is required.

1.2 On the face of it there is no shortage of social scientific writing on subjects that are clearly related to climate change. Over the years these have ranged from grand and occasionally sweeping statements about forces of globalisation and the geopolitics of consumption and production (Giddens 2009; Urry 2010) through to rather more specific claims regarding the potential for ecological modernisation (Mol, Sonnenfeld et al. 2009); the role of the green consumer (Spaargaren 2000) or the work entailed in establishing climate change as a topic of scientific, popular and academic debate (Shackley and Wynne 1996). Nor is there any lack of microsocial studies homing in on the thoughts and experiences of individuals committed to low carbon lifestyles (Hobson 2001; Nye and Hargreaves 2009). Numbers of social researchers analyse environmentally responsible businesses and communities and many others are busy figuring out how to promote public engagement and persuade people to curtail resource intensive habits.

1.3 More abstractly, the task of analysing and understanding patterns and processes of social change is core-business for the social sciences and for sociology in particular. On this topic and on others related to massive, rapid and systemic transformations in technology, culture and ordinary ways of life, sociology has always had a lot to say.

1.4 So what is the problem? Is it that literature of the kind referred to above is not 'really' sociological, or that sociologists of climate change fail to represent the full range of what sociology has to offer, or that a sociology of climate change exists, but is ignored in policy and academic debate? In commenting on these different diagnoses I reflect on the ways in which agendas are formed within the discipline and on the politics of social scientific knowledge as that plays out in climate change policy.

1.5 I am not about to determine what does and does not count as sociology but I agree that when it comes to climate change, the field has been divided. Accordingly, it seems to me that there is something of a missing middle between those who write about political-economic contexts and institutional arrangements and those whose agendas revolve around the drivers and barriers of individual behaviour. I believe that this middle ground is territory that sociologists should inhabit and that more analyses of how "systems of economic, technological and social practice" evolve (Urry 2010) would help address a number of contemporary challenges including those relating to climate change.

1.6 However, I do not think the reason for sociology's marginal position in the policy arena has to do with a shortage in the supply of suitably subtle, appropriately complex meso-level sociological research. To put it bluntly, I doubt that it would make much difference if sociologists responded to all of Urry's injunctions, not even if they did so en masse or overnight. This is because sociology does not control the world in which it operates, or the fate that befalls the ideas and insights it produces. Sociology's status is not simply due to the actions and inactions of sociologists themselves. Nor is the appeal and the dominance of economics some kind of accident waiting to be reversed.

1.7 As currently configured, the climate change policies of many nations revolve around concepts of social change, responsibility and governance which are remarkably consistent with theoretical traditions prevalent in economics and psychology. Accordingly, addressing the human dimensions of climate change is, in 
essence, a matter of incentivising, persuading and encouraging individuals to do their bit and to "kick the habit" (United Nations Environment Programme 2008) of excessive resource consumption. Such approaches are comfortable and familiar and they resonate with what many people think about the world and how it works. They are also simple to defend: if people do not respond to messages and incentives as predicted, it must be because some barrier is preventing them from doing so. But perhaps their most crucial political advantage is that they take government itself more or less entirely out of the frame (Shove 2010).

1.8 It is at this point that differences in academic concepts and representations of societal change bleed into rather broader questions about the role of the state. Analytically, certain traditions of enquiry take change to be an outcome of factors and drivers bearing down on individual behaviour. Others view the social world as an emergent system characterised by processes of feedback, interdependence and mutual constitution. These theoretical-cum-methodological positions lead to different interpretations of what policy can do and are often, but not necessarily, associated with contrasting views about what policy makers should do.

1.9 In any event, the upshot is that problem definitions (and potential solutions) are routinely framed in such a way that policy makers are unable to see the part they play in shaping and sustaining unsustainable institutions and infrastructures, and are correspondingly unable to engage with systemic analyses of the type that sociology might offer. As John Urry also concludes, "to the extent that economics is dominant in investigating changing climates, the less likely policy makers will be able to engender the social-andphysical preconditions for a low carbon economy-and-society" (Urry 2010).

1.10 So where does this leave us? Does society's salvation lie in sociology (or at least in a particular kind of sociology) coming to the rescue and in some heroic move overthrowing dominant, problematically individualist paradigms and the powerful disciplines that support them? Is there still scope for sociology to arrive and in the nick of time define and provide intellectual justification for styles of policy making that are genuinely capable of engaging with the challenges of climate change? Probably not, and almost certainly not by commandment alone! Does sociology's salvation then lie in some form of climate change shock, a catastrophe powerful enough to disrupt the status quo and demonstrate the need for approaches founded on and informed by radically different theories of the social world and how it works? This is perhaps more plausible but both scenarios are a bit extreme.

1.11 Somewhere in between there are signs that the landscape of politics and knowledge is on the move. Little niches are opening up within and at the margins of policy-as-normal. For example, the Scottish Government (2010) has recently come up with a list of "ten key messages about behaviour change". Despite the title, some suggestions point in an unusual direction. There is explicit recognition that technologies and infrastructures matter and that governments can take on more responsibility for "editing" peoples' choices and for shifting shared conventions of normal and appropriate practice. The European Commission has also issued a call for social research on climate change that is explicit about the need to go beyond the behavioural perspective in order to address structural changes in consumption and production european (2010: 55 ).

1.12 If I were to make any prescriptions l'd advocate thoughtful intervention designed to exploit these few cracks in the system. I would also make a strong case for proceeding by means of methodological example. Comparative research can reveal the extent to which water and energy consuming practices are embedded in, and constitutive of, infrastructure and convention and can do so silently, effectively and without fanfare (Wilhite, Nakagami et al. 1996). Changing the terms in which problems are cast is also vital: however subtle, switching language matters. Simple pedagogic techniques, like talking about the services energy makes possible - cooking, lighting, heating and cooling - and not "energy" itself, turns attention to the histories and trajectories of what people do, locating this not as an outcome of individual choice but as part and parcel of a much more extensive process of sociotechnical change (Shove 2003).

1.13 Given the urgency of climate change this might sound a bit too tame, and a bit slow, but given the wider politics of knowledge re-framing is an ambitious and not a cautious strategy. If the emphasis turns from energy to heating and cooling new questions come into view. Cast in these terms, debates about energy policy are unavoidably debates about what conditions of comfort might possibly mean in a really low-carbon society. How much will people need to sweat, and when and how will governments move to overthrow unsustainable conventions like those of maintaining buildings to a steady 22 degrees $C$ ? To give another example, initiatives to promote cycling would be thought through in terms of their relation to existing car-based regimes, provoking discussions about just how far policy might go in deliberately unpicking systems of automobility and about how much cycling society could in fact take. These big questions would be out in the open, and not swept under the policy mat. 
any less performative than that which is rooted in economics/psychology. There is, however, a chance that the types of problems, solutions, methods and concepts reproduced in such a scenario would be better suited to the challenges ahead. And if the policy climate is changing, even a bit, then there is a chance that sociologists and their new-found, new-style policy colleagues will be able to work together to articulate, imagine and promote remarkable and significant transitions towards much lower carbon ways of life. Helping this come about is in essence a matter of engendering and embedding what C. Wright Mills (1970 [1959])describes as a sociological imagination within the policy world and the wider public - not of commanding yet more sociologists to produce yet more marginalised studies of climate change.

\section{References}

EUROPEAN COMMISSION. (2010). "Work Programme 2011, Cooperation Theme 6, Environment (including climate change) ", available from ftp://ftp.cordis. europa.eu/pub/fp $7 /$ docs/wp/cooperation/environment/f-wp201101_en.pdf.

GIDDENS, A. (2009). The Politics of Climate Change. Cambridge: Polity.

HOBSON, K. (2001). "Sustainable Lifestyles: rethinking barriers and behaviour change" in Cohen, M. and Murphy, J. (eds) Exploring sustainable consumption. Amsterdam: Pergamon. [doi:10.1016/B978008043920-4/50014-8]

MILLS, C. W. (1970 [1959]). The sociological imagination. Harmondsworth: Penguin.

MOL, A. P. J., Sonnenfeld, D. A., et al. (eds) (2009). The ecological modernisation reader: environmental reform in theory and practice. Abingdon, Routledge.

NYE, M. and Hargreaves, T. (2009). "Exploring the Social Dynamics of Proenvironmental Behavior Change." Journal of Industrial Ecology 14(1): 137-149. [doi:10.1111/j.1530-9290.2009.00193.x]

SHACKLEY, S. and Wynne, B. (1996). "Representing Uncertainty in Global Climate Change Science and Policy: Boundary-Ordering Devices and Authority." Science, Technology \& Human Values 21(3): 275-302. [doi:10.1177/016224399602100302]

SHOVE, E. (2003). Comfort, cleanliness and convenience : the social organization of normality . Oxford: Berg.

SHOVE, E. (2010). "Beyond the ABC: climate change policy and theories of social change." Environment and Planning A 42(6): 1273-1285. [doi:10.1068/a42282]

SPAARGAREN, G. (2000). "Ecological modernization theory and domestic consumption." Journal of Environmental Policy \& Planning 2(4): 323 - 335. [doi:10.1080/714038564]

THE SCOTTISH GOVERNMENT. (2010). "10 Key messages about behaviour change." Available from <http://www.scotland.gov.uk/Topics/Research/by-topic/environment/social-research/Remit/events/KeyMessages $>$.

UNITED NATIONS ENVIRONMENT PROGRAMME. (2008). "Kick the Habit: a UN guide to climate change neutrality." available from <http://www.unep.org/publications/ebooks/kick-the-habit/>.

URRY, J. (2010). "Consuming the Planet to Excess." Theory, Culture \& Society 27(2-3): 191-212. [doi:10.1177/0263276409355999]

URRY, J. (2010). "Sociology Facing Climate Change." Sociological Research Online 15(3): 1.

WILHITE, H., Nakagami, H., et al. (1996). "A cross-cultural analysis of household energy use behaviour in Japan and Norway." Energy Policy 24(9): 795-803. [doi:10.1016/0301-4215(96)00061-4] 